\title{
UN ENSAYO SOBRE EL PROBLEMA DE LA DISCRECIONALIDAD Y LA MALA COMPRENSIÓN DE LOS PRECEDENTES JUDICIALES"
}

Fecha de recibido: 22 de julio de 2014

Lenio Luiz Streck

Fecha de aprobado: 24 de octubre de 2014

Artículo de reflexión

Forma de citación. Streck, L. (2015). Un ensayo sobre el problema de la discrecionalidad y la mala comprensión de los precedentes judiciales. Revista Prolegómenos. Derechos y Valores, 18, 35, 67-80.

\section{Resumen}

El artículo consiste en un análisis de la discrecionalidad judicial entendida como característica del positivismo jurídico desde la manera como se comprenden los precedentes judiciales en Brasil. El objetivo principal del texto es demostrar que los precedentes judiciales se aplican de forma arbitraria por la jurisprudencia y la doctrina brasileña, revelando los abusos interpretativos por parte del poder judicial y el debilitamiento de la democracia. El método de abordaje es el hermenéutico-fenomenológico, esto es, reconstrucción crítica del fenómeno de la interpretación de los precedentes judiciales. Como resultados, el documento muestra la fragilidad de la democracia constitucional ante el arbitrio interpretativo de los tribunales judiciales desde el modo como se aplican los precedentes en Brasil.

\section{Palabras clave:}

Discrecionalidad, decisión judicial, precedentes judiciales.

\section{AN ESSAY ON THE PROBLEM OF DISCRETION AND WRONG UNDERSTANDING OF COURT PRECEDENTS}

\begin{abstract}
This article is an analysis of judicial discretion seen as a characteristic of legal positivism from the way judicial precedents are understood in Brazil. The main aim of this paper is to demonstrate that judicial precedents are applied arbitrarily by Brazilian jurisprudence and doctrine, revealing the interpretative abuses by the judiciary and the weakening of democracy. The approach is an hermeneutic-phenomenological method, that is, a critical reconstruction of the phenomenon of judicial precedent interpretation. As a result, the document shows the fragility of constitutional democracy before the interpretive discretion of courts from the way precedents are applied in Brazil.
\end{abstract}

" Artículo producto del proyecto de investigación "Hermenéutica y teoría de la decisión". Entidad patrocinadora: Programa de Posgrado en Derecho, Universidad de Vale do Rio dos Sinos (Unisinos) y Consejo Nacional de Desarrollo en Ciencia y Tecnología.

** Maestro y doctor en Derecho por la Universidad Federal de Santa Catarina. Posdoctoral en la Universidad de Lisboa. Profesor de Unisinos, Programa de Posgrado en Derecho (maestría y doctorado) en el área de concentración en Derecho Público. Profesor permanente Unesa-RJ-Roma Tre (Scuola Dottorale Tullio Ascarelli), Facultad de Derecho, Universidad de Coimbra (Capes-Grises Acuerdo Internacional) y la Facultad de Derecho de la Universidad de Lisboa. Correo electrónico: lenio@unisinos.br 


\title{
Keywords:
}

Discretion, judicial decision, judicial precedents.

\section{UM ENSAIO SOBRE O PROBLEMA DA DISCRICIONARIEDADE E A MÁ COMPREENSÃO DOS PRECEDENTES JUDICIAIS}

\begin{abstract}
Resumo
O artigo propõe uma análise da discricionariedade judicial como característica do positivismo jurídico, da ótica dos modos de compreensão dos precedentes judiciais no Brasil. Particularmente, visa-se demonstrar a aplicação arbitrária dos precedentes judiciais pela jurisprudência e doutrina brasileiras, evidenciando os abusos interpretativos do Poder Judiciário e o consequente enfraquecimento da democracia. Aborda-se a questão proposta, por meio do método hermenêutico-fenomenológico, quer dizer, pela reconstrução crítica do fenômeno da interpretação dos precedentes judiciais. Como principal resultado, este trabalho leva em linha de conta a fragilidade da democracia constitucional decorrente do arbítrio interpretativo dos Tribunais no âmbito da aplicação dos precedentes judiciais no Brasil.
\end{abstract}

\section{Palavras-chave:}

Discricionariedade, decisão judicial, precedentes judiciais.

\section{INTRODUCCIÓN}

Frente a un estado del arte representado por el predominio del positivismo, que sobrevive a partir de las más diversas posturas y teorías que se sostienen de un modo u otro en el esquema sujeto-objeto, la problemática se agrava con una especie de protagonismo del sujeto-intérprete en pleno paradigma de la intersubjetividad. Asumimos que, más que posibilidad, la búsqueda de respuestas correctas es una necesidad.

Sin embargo, la respuesta correcta no significa que sea definitiva, como es el caso de la institucionalización de los precedentes vinculantes. Parece evidente que un sistema jurídico que adopte precedentes vinculantes no tiene en esto un "mal en sî". A fin de cuentas, la integridad del derecho también se construye desde el respeto a las decisiones judiciales.

De hecho, la integridad está umbilicalmente conectada a la democracia, exigiendo que los jueces construyan sus argumentos de forma integrada al conjunto del derecho (Dworkin, 1986). Se trata pues de "consistencia articulada". Con eso, se aleja tanto del punto de vista objetivista, por el cual "el texto carga consigo su propia norma" (ley es ley en sí), como del punto de vista subjetivista-pragmatista, para el cual-aprovechando la relación texto-norma- la norma puede hacer que el texto se pierda o, aun, lo que es peor en ciertas situaciones, cuando el juez o el tribunal deciden contra legem, que la regla creada sea otra que no aquella "acusada" de estar (o de haber estado) en el texto. Ese texto, en estos casos - y estaremos volviendo al realismo jurídico-, acaba encubierto no por la nueva norma (sentido), sino por otro (nuevo) texto, lo que puede con facilidad ocurrir cuando se hace la edición de precedentes vinculantes. El problema es que los precedentes (brasileños) tienen pretensión de universalidad que es incompatible con un derecho que debe construirse a partir de la discusión de los casos concretos. Explicándolo mejor: los precedentes 
vinculantes - del modo como la dogmática jurídica los entiende- encarnan una instancia metafísicamente controladora de sentidos, o sea, a través de ellos, se cree que es posible manejar conceptos sin las cosas (sin las multiplicidades y las peculiaridades de los casos específicos).

En efecto, de la forma como se comprenden los precedentes vinculantes en el interior del pensamiento dogmático del derecho, ellos se ponen como sucedáneos de los conceptos universales propios de la metafísica clásico-especialista, con el agravante, aquí, de que se les crean desde una institucionalización de subjetivismo, axiologismos y realismos, variaciones del esquema sujeto-objeto.

Es cierto que los precedentes no son respuestas a los casos pasados, sino una intención de abarcamiento de todas las futuras hipótesis de aplicación de determinada regla jurídica. Los precedentes convirtieron el lenguaje en simple vehículo de conceptos. Son, así, antihermenéuticos, porque no interrogan el origen de los significados, es decir, por el procedimiento de precedente, se usan palabras -transformadas en artículos- sin antes cuestionarlas en su relación con las cosas que estas deben tratar.

Se forma así, un círculo vicioso en el interior de la dogmática jurídica: primero, ante el predominio del positivismo se admiten interpretaciones discrecionales y arbitrarias (como sostienen juristas de los más variados matices, no hay cómo impedir la "creatividad" de los aplicadores, como si estuviéramos condenados al solipsismo $)^{1}$, todo en nombre de la ideología del caso concreto para después "congelarse" ese sentido, como si fuera posible cubrir todas las futuras hipótesis de aplicación. O sea que, en nombre del "caso concreto" se institucionaliza una especie de "grado cero de sentido". Pero ese

$1 \quad$ Es de esta manera que se puede observar cierta imbricación-consciente o inconsciente-de los paradigmas metafísicos clásico y moderno en el interior de la doctrina brasileña (y extranjera). Se trata entonces de un problema paradigmático. caso desaparece en el intermedio del proceso de conceptualización. Para evitar malentendidos: es evidente que el derecho es "una cuestión de caso concreto". Pero del modo como se procede en la dogmática jurídica, el "caso concreto" -que posee particularidades (él, después de todo, no es un estándar jurídico) - deja de ser un caso, porque queda obnubilado por la pretensión de universalización que se hace a partir de él, problemática bien presente en la proliferación de artículos que la cultura de baja producción intelectual "institucionalizó" en el campo jurídico.

En tanto que no se respeta la integridad del derecho y la fundamentación se da con base en conceptos prêt-à-pôrter (véase que el precedente, de por sí, sirve como soporte para una decisión, como desde hace mucho ya ocurría con cualquier artículo o enunciado) se tiene un sistema que admite multiplicidad de respuestas (decisiones). La consecuencia es un sistema "desgobernado", a partir de una sucesión interminable de recursos (nótese la proliferación de la bizarra figura de los embargos de declaración), que lejos de ofrecer respuestas adecuadas, solo reproducen sumarios prêt-àpôrter. La ausencia de una tradición - en el sentido que trata Gadamer (1990) - que obligue a los magistrados a obedecer la integridad del derecho hace que los jueces de primera instancia sean apenas un rito de paso para la segunda instancia. Esto también vale para los tribunales o cortes superiores.

En ese orden de ideas, en virtud de la multiplicación de procesos (recursos de los más diversos) y para controlar ese caos, se busca construir conceptos abstractos con pretensiones de universalización, como si fuera viable que una norma jurídica abarque todas las hipótesis (futuras) de aplicación. Y crece, consecuentemente, la importancia de los precedentes, que pasan a tener la función de corregir lo que el propio positivismo ha provocado.

El establishment jurídico, con fuerte preeminencia de la escuela instrumentalista del proceso, 
siempre apostó al protagonismo judicial. Basta observar cómo el proceso civil se transformó a lo largo de los años. Los juzgados colegiados en juzgados monocráticos; los precedentes y jurisprudencia imperantes se convirtieron en obstáculo, incluso para la admisión de los recursos (también de agravios).

En síntesis, los precedentes pueden constituirse en un importante mecanismo de refuerzo a la integridad y coherencia del derecho. Pero para ello se les debe entender de manera idónea, es decir, como textos jurídicos, e implementarlos justamente desde el respeto a la integridad y a la coherencia del derecho. Se deben comprender de forma correcta tales circunstancias como la estricta obediencia del deber de fundamentar las decisiones. Así, pueden contribuir para la construcción de respuestas ajustadas a la Constitución.

La cuestión del combate al "estado de naturaleza hermenéutico" no reside en los precedentes ${ }^{3}$, sino en la pretensión metafísica de su uso (y a veces en su ilegalidad/inconstitucionalidad). Se refiere a que de todos modos, en ocasiones el propio precedente se aplica -él mismo- para ir más allá de sus límites semánticos. Un ejemplo interesante es el de la Súmula Vinculante n ${ }^{\circ} 10$ del Supremo Tribunal Federal ("Viola la cláusula de reserva de plenario la decisión de órgano fraccionario de tribunal que, aunque no declare expresamente la inconstitucionalidad de ley o acto normativo del poder público, aleja su incidencia en su totalidad o en parte"). Aquí, o el precedente es tautológico y refuerza la dicción del artículo 97 de la Constitución Federal, o va más allá del dispositivo constitucional al pretender, por ejemplo, afectar la interpretación conforme y la nulidad parcial sin reducción de texto. En este caso, ella sería inconstitucional.

Expliquemos el porqué: así como no hay que enviar al Senado una decisión de nulidad parcial sin reducción de texto (también llamada de decisión de inconstitucionalidad parcial cualitativa) hecha por el STF, no cabe exigir incidente de inconstitucionalidad, no habiendo, con eso, violación al full bench (art. 97 de la CF). Eso es porque, tanto en la interpretación conforme a la Constitución como en la nulidad parcial sin reducción de texto, no existe expurgación del texto o parte del texto normativo, solo hay un alejamiento de una de las incidencias del texto. Como hay varios sentidos, y el tribunal opta por uno de ellos (en la interpretación conforme hay una adición de sentido), en la nulidad parcial cualitativa el resultado hermenéutico hace que el texto permanezca con un minus en la interpretación.

En la medida en que en ambas hipótesis el texto permanece en su literalidad, no se debe hablar de incidente de inconstitucionalidad. Por el contrario, no habría cómo operativizar el incidente de inconstitucionalidad por el sentido de un texto. En pocas palabras, el precedente 10 se aplica solo a los casos en que hay inconstitucionalidad con reducción de texto (o sea, en las hipótesis en que los órganos fraccionarios o los propios tribunales hacen un "desvío" hermenéutico en el art. 97 de la CF). Por lo tanto, la SV 10, entendida adecuadamente, no es inconstitucional. Inconstitucionales son las decisiones de tribunales que la aplican más allá de sus límites semánticos ${ }^{2}$, abarcando cualquier tipo de interpretación conforme o nulidad parcial sin reducción de texto.

2 Estos se interpretan como los sentidos originarios del uso pragmático del lenguaje que componen el enunciado. Es una especie de "mínimo es" que resulta del uso lingüístico. Esto es, en el ámbito de la lección de Gadamer, si quieres decir algo acerca del sentido de un texto, deja por lo menos que ese texto te diga algo (teniendo en cuenta que el dispositivo no sea inconstitucional, por supuesto). Así, si una ley establece la prohibición de circulación de bicicletas en parques los fines de semana, podremos -superada la cuestión de la validez constitucional de la norma- discutir los límites del horario, el alcance de la acepción de parque (¿las plazas se incluirían?), etc. Sin embargo, hay un punto que parece indiscutible: la prohibición. O sea, el intérprete no podrá transformar la prohibición en permisión, como, por ejemplo, lo hizo el STF al interpretar el art. 212 del CPP. 


\section{A. La respuesta correcta (adecuada a la Constitución) como derecho fundamental del ciudadano}

En (duros) tiempos de pospositivismo, estamos condenados a interpretar. Gadamer (1990) nos enseñó que interpretar la ley es un acto productivo y no reproductivo, mostrando la superación de la hermenéutica clásica por la hermenéutica filosófica. Saltar de la auslegung a la sinngebung, decía el maestro de Tubinga. Un principio (una ley, un precedente), una vez enunciado, ocupará campos para los cuales no haya sido dimensionado, recordemos, por ejemplo, a Laurence Tribe y Michael Dorf (2006), apoyados en la lección del juez Cardozo.

El problema es que la pretensión de componer un cuerpo de leyes coherente y consistente requiere de la elaboración de principios constitucionales, con lo que nos atrevemos a pensar que tal circunstancia acarrea (o proporciona) una mayor apertura interpretativa y, en consecuencia, un retroceso a la discrecionalidad del juez/intérprete (siempre recordando que los términos "discrecionalidad" y "positivismo" se aplican según el debate entre Dworkin y Hart (1989); sin dejar de pensar que en Brasil la "cuestión de la discrecionalidad" asume contornos dramáticos, en los que esta y la arbitrariedad son lados de la misma moneda; y sin olvidar que en terra brasilis, la mezcla de las posturas objetivistas y subjetivistas hace que un mismo tribunal asuma posiciones exegéticas -por las cuales la "ley vale todo"-y posturas voluntaristas en las que se ignora la ley). Y luego, correríamos en búsqueda de métodos que nos indiquen el camino para solucionar las "indeterminabilidades" de los textos jurídicos.

Pues si un texto legal -o un precedente, que también es un texto- lograra contener todas las hipótesis de aplicación, sería una ley perfecta. Mutatis mutandis, es como si consiguiéramos hacer un mapa que se configurara perfectamente con el globo terrestre. Pero ¿qué ventajas hay en eso? Pues, iun mapa perfecto no sería más que el propio planeta! Dicho de otro modo: si se pudiera transmitir la realidad tal como es, estaríamos ante una paradoja. Y paradoja es algo sobre lo que no podemos decidir.

De ahí el enigma que suscita la figura de Hermes, que ya nace engañando al propio padre. $Y$ Hermes se hizo muy poderoso. Sin él, no sabríamos qué habían dicho los dioses. En realidad, nunca se supo qué dijeron los dioses; ise supo solo lo que Hermes dijo que los dioses dijeron! Sabemos, entonces, del problema originario de la "subjetividad" de Hermes y de la complejidad que eso representa (por ejemplo, ¿́cuál es el límite del nivel de abstracción de la generalidad de las sentencias de Hermes?). Pero también conocemos, en la metáfora, que el acceso directo al lenguaje de los dioses es imposible. Por ello surge la pregunta inevitable: si fuera posible ese "acceso directo", ¿qué utilidad tendría para los hombres, que, en definitiva, no son dioses?

Quizá hayamos recibido el castigo de Sísifo: rodamos la piedra hasta el límite del logos apofántico $y$ de inmediato, somos lanzados inexorablemente de vuelta a nuestra condición de posibilidad: el logos hermenéutico. Es él quien nos anticipa las posibilidades de la comprensión. Y los métodos (o varios métodos positivistas o "pospositivistas") terminan (siempre) llegando tarde. Si pensamos que el método es indispensable para la seguridad y la racionalidad en la atribución de los sentidos, o que debemos desordenar al intérprete/ aplicador de los discursos de fundamentación/ justificación (begründungsdiskurs), "poniéndole a disposición" discursos antes justificados (porque no confiamos en la razón práctica), aún así -o exactamente por eso- deberemos responder al siguiente planteamiento: ¿qué hacer con la precomprensión?

Por último, si pensamos que la destrucción del método (cánones, criterios ponderativos o postulados) tendrá como efecto un relativismo en la interpretación, volveremos a equivocarnos. Es más, esa es una grave falta que cometen los críticos de la hermenéutica filosófica.

Vale destacar entre esos críticos al iusfilósofo Matthias Jestaedt (2002), para quien las 
decisiones creativas (activistas o "intervencionistas") del Tribunal Constitucional Alemán (y todos nos percatamos de la dimensión de ese poder creativo) son positivistas porque la interpretación de la Ley Fundamental, institucionalizada en su jurisprudencia, sustituye la propia Ley Fundamental. Con eso, es posible entender que para Jestaedt (2002) el paradigma iuspositivista es aquel que tiene la capacidad de determinar lo que es "positivo". Así, para él, la dogmática constitucional alemana se rinde (rindió) al positivismo jurídico aplicado al Tribunal Constitucional, una vez que desde hace mucho ella, la dogmática, ya no se remite a la Grundgesetz, sino a la colección de fallos.

Hasta aquí, no habría grandes discordancias con el pensador alemán. La divergencia comienza cuando Jestaedt (2002) pone como "culpable" de ese positivismo a la hermenéutica de matriz gadameriano-heideggeriana (a veces llamada por él de filosofía hermenéutica $y$, en otras, de hermenéutica filosófica, icomo si fueran lo mismo!). Para el iusfilósofo en comento, el Tribunal Constitucional viene haciendo una "jurisprudencia de la concretización", tesis que giraría alrededor del pensamiento fundamental de la hermenéutica filosófica.

¿Y por qué sería así? La respuesta de Jestaedt (2008) es que por no existir -en la hermenéuticauna comprensión sin aplicación, aquello que debe ser comprendido solamente se materializa en el proceso de aplicación. De ese modo, la idea de una lex ante casum preexistente, que se pueda expresar únicamente descubriendo qué "se le ha puesto", resultaría en una quimera en el plano de la teoría del conocimiento, una vez que la interpretación significa siempre concretización. La interpretación se explica como "producción de derecho", por medio de la concretización creativa de las normas (Jestaedt, 2008).

En la secuencia, el autor equipara la hermenéutica filosófica, que estaría en la raíz de la jurisprudencia de la concretización, con la jurisprudencia del discurso habermasiana, momento en que también compara la jurisprudencia del discurso con la ponderación, lo que, de por sí, ya representa un problema complejo, en tanto que la teoría habermasiana y la alexyana, que sistematizó de manera sofisticada la ponderación, son en absoluto antiéticas. Lo que sucede es que esas conclusiones de Jestaedt (2008) son producto de una equivocada lectura de Heidegger y Gadamer, sobre todo del último. De hecho, cuando Gadamer afirma que interpretar es aplicar, por lo tanto, superando las tres subtilitas (inteligendi, explicandi y aplicandi), no quiere decir que él haya sustituido la interpretación por la aplicación o la comprensión por la concretización. Parece que en eso reside la equivocación central de autores como Jestaedt (2008). Lo que sostiene Gadamer (1990) es que no hay cómo escindir la interpretación de la aplicación. Friedrich Müller (2005), padre del pospositivismo, también defiende esa tesis, y ha entendido muy bien esa sutileza de la obra de Gadamer.

Es decir, la compleja hermenéutica gadameriana se soporta en el círculo hermenéutico y en la tradición. No tiene sentido aseverar que en la hermenéutica la ley (ante casum, o sea, el texto de la ley, para usar las palabras de Jestaedt [2008]) sería una quimera. Más aún, es necesario que quede claro que Gadamer (2008) no desplaza el "polo de tensión" para la concreción. Para el autor, así como para Müller (2005), la concretización (applicatio) no es un hecho que ignora la lex ante casum. Al contrario, eso transformaría a Gadamer (1990), o la hermenéutica por él profesada, en una postura pragmatista/nominalista (por ende, positivista).

Si pensamos que la hermenéutica es ese modo "concreto" de llegar a un sentido ignorado (incluso del texto), estaremos sepultando uno de los teoremas esenciales de la filosofía hermenéutica que ha redundado en la hermenéutica filosófica, la diferencia ontológica entre ser y ente. El ser solo es en el ente y el ente solo es en su ser. La hermenéutica no guarda ninguna relación con relativismos o nihilismos. En realidad, es de Gadamer la frase expresa en Verdad y método: wer einen text verstehen will, ist vielmehr bereit, sich von ihm etwas zu sagen lassen (si quieres 
decir algo sobre un texto, deja primero que el texto te diga algo) (1990, p. 60).

Para evidenciarlo: desde el inicio siempre quedó claro que la hermenéutica, que sirve de base para estas reflexiones, no abre espacios para arbitrariedades, relativismos, decisionismos ni discrecionalidades. Por supuesto que eso no representa una "prohibición de interpretar", como, de hecho, se explica en el presente artículo.

De todos modos, cabe preguntarse: ¿cuál sería la validez (o el sentido) de una hermenéutica jurídica que admitiera "cualquier respuesta"? ¿De una hermenéutica que consintiera, como Kelsen (1979), que la interpretación judicial es un acto de voluntad? ¿Cuál sería la utilidad de una hermenéutica que aceptara incluso múltiples respuestas para un mismo caso "concreto"? ¿Cuál sería la razón de ser una teoría hermenéutica que admitiera que el derecho es aquello que el "intérprete autorizado" dice lo que es? Sin temor a equivocarse, nada más, nada menos, eso sería volver al último principio final de la metafísica moderna: la voluntad del poder (wille zur macht). Y, como consecuencia, se estaría admitiendo un "grado cero en la significación" y, por ende, un constante estado de excepción hermenéutico. La hermenéutica sería, pues, prelingüística. Pero entonces, iya no sería hermenéutica! Por eso, la necesidad de que existan respuestas correctas en el derecho (véase Streck, 2014).

Aquí cabe una vez más la advertencia: el no relativismo propugnado por la hermenéutica y su aversión a la discrecionalidad no significan prohibición de interpretar, con la exclusión de la subjetividad, de las voluntades de los deseos, de las preferencias personales etc., de cada sujeto-intérprete. En definitiva, ies menester aclarar que la hermenéutica aquí sostenida no excluye la subjetividad inherente a cualquier actividad comprensiva! Repetimos: la superación del esquema sujeto-objeto significó el derroque de la filosofía de la conciencia, como también significó la muerte del sujeto de la relación de objetos (a fin de cuentas, ella ahora se convierte en sujeto-sujeto). Sucede que, al contrario de lo que pasa en otras teorías lingüístico-discursivas, en la hermenéutica el sujeto del esquema sujetoobjeto no ha sido sustituido por una estructura, una red de comunicación o un sistema.

Pero atención, reconocer que cada sujeto tiene preferencias personales, intuiciones, valores, etc. -lo que es inherente al modo propio de ser-en-el-mundo de cada persona- no quiere decir que no pueda haber condiciones de verificación sobre la corrección o veracidad acerca de cada decisión que ese sujeto toma (principalmente cuando se trata de un juez). Nada de eso denota que dependamos solo de los aspectos lingüísticos o límites semánticos de los textos jurídicos para esa desiderata.

En efecto, siempre hay un significado del texto (y el texto es siempre un evento) que no adviene tan solo del "propio texto", sino de un análisis de decisiones anteriores, de la aplicación coherente de tales decisiones y de la compatibilidad del texto con la Constitución. El grado de exigencia de fundamentación/justificación de la interpretación alcanzada aumentará en la medida en que esa significación atribuida al texto se aleje de los "aspectos lingüísticos". Se trata de convencer y de establecer amplias posibilidades de control de la decisión. Ese es el espacio para la respuesta correcta (adecuada a la Constitución). Se trata ide un derecho fundamental del ciudadano!

Hay, entonces, una relación umbilical entre la exigencia de fundamentación y el derecho fundamental que cada ciudadano tiene a una respuesta correcta (adecuada a la Constitución). Como bien señala Flaviane Barros (2008), aunque el juez sea una persona con convicciones e historia de vida, la limitación a su subjetivismo y a su parcialidad ocurre justamente en el impedimento de una fundamentación que extrapole los argumentos jurídicos y en la obligatoriedad de construir la decisión con la argumentación participada de las partes que, como partes contradictorias, puedan discutir la cuestión del caso concreto, 
de manera que la decisión racional se garantice en términos de coherencia normativa a partir de la definición del argumento más idóneo al caso. Así, el objetivo es garantizar que un juez, incluso con sus convicciones, no presente un juicio axiológico, en el sentido de que todos los ciudadanos compartan de la misma concepción de vida, o que los valores expuestos allí en la sentencia vinculen normativamente a todos los demás sujetos del proceso.

Si las concepciones metafísicas sobre el derecho se sostienen en la atribución de sentidos in abstracto -y por eso sustentan la posibilidad de la existencia de múltiples respuestas-, es porque la interpretación ocurre en etapas, escindiendo interpretación y aplicación (nótese que hay diferentes teorías argumentativas que apuestan inclusive por la posibilidad de "ponderación por etapas", extendiendo el método más allá de la colisión de principios). Pues es exactamente en este punto donde reside la distinción entre la hermenéutica y las diversas teorías discursivo-procedimentales. En otras palabras, es la inescindibilidad entre interpretar y aplicar que representará la ruptura con el paradigma representacional-metodológico. Y es el círculo hermenéutico, referido hasta la saciedad en las fases anteriores de estas reflexiones, que se constituirá en condición de ruptura del esquema (metafísico) sujeto-objeto, en él introduciendo el mundo práctico (facticidad) que sirve para cimentar esa travesía, hasta entonces romanceada en la y por la epistemología. No hay como aislar la preconcepción.

La admisión de múltiples respuestas se asocia con el conceptualismo de la regla, que "abarca" (todas) las posibles "situaciones de aplicación" de forma anticipada, con independencia del mundo práctico (sobre la distinción reglaprincipio, consúltese la profunda investigación de Tomas de Oliveira, 2008). Es decir, acoger múltiples respuestas tiene que ver con el análisis del lenguaje, con el semantic sense. En ese "mundo", lo que vale es el enunciado, esto es, todas las otras formas de lenguaje y todos los otros modos de hablar del objeto de análisis se resumen al enunciado. Para explicar mejor ese fenómeno es posible expresar -con base en Gadamer (1990) - que la posibilidad de múltiples respuestas está calcada en el logos apofántico, cuya función es significar el discurso; o sea, la proposición cuyo único sentido es el de realizar el apofainesthai, el mostrarse lo que se ha dicho. Es una proposición teórica en el sentido de que se abstrae de todo lo que no dice de forma expresa. Lo que constituye al objeto del análisis y al fundamento de la conclusión lógica es solo lo que ella misma revela por su decir. La hermenéutica no rechaza que un texto (un enunciado lingüístico) tenga varios significados. No se niega la vaguedad y la ambigüedad del lenguaje. No es esa la discusión. El problema es que las posturas analíticas (donde se insiere la dogmática jurídica lato sensu) estiman viable agotar los significados de los textos in abstracto (por eso, el semantic sense). De ahí la proliferación de los artículos y la cultura de la estandarización del derecho. Los precedentes vinculantes son un ejemplo privilegiado de ese intento semántico de abarcar los sentidos antes de la aplicación.

Al contrario de eso, para la hermenéutica adoptada, no hay respuestas antes de las preguntas. Reiteramos, no hay textos sin cosas. Puede haber cientos de definiciones para la palabra "hurto". Sin embargo, el evento hurto -momento único en que se dará el sentido de un "hurto real"ocurre solo de un modo. Ese "modo" se da a partir de la application. La decisión sobre ese evento se dará a partir de la reconstrucción institucional del derecho, de la coherencia y de la integridad. La decisión acerca del fenómeno no partirá de un grado cero, tampoco sucederá por el "acoplamiento" de un sentido previamente elaborado (sintáctica y semántica) a un "hecho desnudo". Es de esa manera que la hermenéutica representa la superación del problema dejado por la discrecionalidad positivista.

Pero, ¿cómo surge y en qué reside la discrecionalidad positivista? La respuesta es sencilla. En tanto que -en el "mundo" del semantic sense-siempre hay un déficit de previsiones 
(es imposible que un texto comprenda todas las posibilidades aplicativas) las posturas positivistas "delegan" al juez para que complete ese vacío de sentido. Esa delegación a favor del poder discriminatorio fragiliza la autonomía del derecho y la propia democracia.

Por eso la necesidad de una teoría de la decisión, para controlar el solipsismo en la aplicación. Observemos: con la excusa de superar el problema de la discrecionalidad/arbitrariedad (subjetivista-axiologista) del juez, no se puede "exentarlo" de la "tarea" de elaboración de discursos de fundamentación (que en la teoría del discurso de Habermas (1997) y Güther (2004) se dan siempre prima facie). Decir que se deben controlar las decisiones judiciales (fundamentación de la fundamentación, como venimos afirmando) no implica un regreso al exegetismo o "prohibición de interpretar". Interpretar es aplicar. Es atribuir sentido. Lo que queremos manifestar es que tal circunstancia no eleva al intérprete a "señor de los sentidos" o a "propietario de los medios de producción de las significaciones".

En resumen, cuando aseveramos el deber de accountability, no estamos simplemente declarando que la fundamentación soluciona el problema original, como por ejemplo, el del libre convencimiento, el de la libre apreciación de la prueba o el de la admisión lato sensu de la discrecionalidad. Accountability, en los moldes en que la proponemos, quiere decir fundamentación de la fundamentación. Eso significa que ni de lejos el inconveniente de la exigencia de fundamentación se soluciona en el ámbito apofántico. Por supuesto que, con todo lo que ya escribimos, ino sería ingenuo pensar que el "deber de fundamentar las decisiones" soluciona(ría) el problema de la decisión...! Un vector de racionalidad de segundo nivel-lógico-argumentativo-no puede ser sustituido al vector de racionalidad de primer nivel, que es la comprensión. Al final de cuentas, ¿̇por qué razón Gadamer (1990) diría que "interpretar es explicitar lo comprendido"? Veamos: explicitar lo comprendido no es poner una capa de sentido a lo comprendido. Ese es el espacio de la epistemología en la hermenéutica (para una comprensión acerca de esta cuestión, consúltese Stein \& Streck, 2011). No nos olvidemos del dilema de las teorías cognitivistasteleológicas: no es posible cruzar el abismo del conocimiento -que "separa" al hombre de las cosas- construyendo un puente por el cual ya se ha pasado. No se puede hacer una lectura superficial del artículo 93, IX, de la $\mathrm{CF}^{3}$. La exigencia de fundamentación no se resuelve con "capas argumentativas". Esto es, el juez no debe "explicar" aquello que lo "convenció", sino que debe explicitar las razones de su comprensión, ofreciendo una justificación (fundamentación) de su interpretación, desde el punto de vista desde el cual demuestra cómo la interpretación ofrecida por él es la mejor para aquel caso (más adecuada a la Constitución o, en términos dworkinianos, correcta), en un contexto de unidad, integridad y coherencia en relación con el derecho de la comunidad política. Quien no logra suspender sus prejuicios, termina produciendo un perjuicio al derecho. Como bien lo expone Dworkin (1989): no importa qué piensan los jueces acerca del derecho, sino el ajuste (fit) y la justificación (justification) de la interpretación que ellos ofrecen de las prácticas jurídicas respecto al derecho de la comunidad política. En especial, el capítulo sobre los hard cases.

Por eso, se puede indicar que una interpretación es correcta y la otra es incorrecta. Nos movemos en el mundo exactamente porque podemos hacer afirmaciones de ese orden. Y siquiera nos damos cuenta de eso. O sea, en la comprensión, los conceptos interpretativos no resultan temáticos como tales, como bien recuerda Gadamer (1990); al contrario, se determinan por el hecho de que desaparecen detrás de aquello de lo que ellos hicieron hablar/aparecer en la y por

\footnotetext{
In verbis: todos los juicios de los órganos del poder judicial serán públicos, y fundamentadas todas las decisiones, bajo pena de nulidad, pudiendo la ley limitar la presencia, en ciertos actos, a las propias partes y a sus abogados, o tan solo a estos últimos, en los casos en que la preservación del derecho a la intimidad del interesado en el sigilo no perjudique el interés público de la información.
} 
la interpretación de Gadamer (1990). Aquello que las teorías de la argumentación o cualquier otra concepción teorético-filosófica (aún) llaman de "razonamiento subsuntivo" o "razonamiento deductivo", es nada más que esa paradoja hermenéutica que se da exactamente porque la comprensión es un existencial (es decir, no nos preguntamos por qué comprendemos algo, por la simple razón de que ya lo comprendimos, lo que hace que nuestra pregunta siempre llegue tarde).

De ese modo, la tesis que sostenemos es una simbiosis entre las teorías de Gadamer (1990) y Dworkin (1986), agregando que la respuesta no es ni la única ni la mejor. Tan solo se trata "de la respuesta adecuada a la Constitución": una respuesta que se debe confirmar en la propia Constitución.

\section{B. Haciendo justicia a Dworkin y Gadamer. De cómo el juez Hércules no es subjetivista (solipsista). Las razones por las que "no se puede decir nada sobre nada"}

Para finalizar - $y$ otra vez con el objetivo de evitar malentendidos-, es necesario comprender que de la misma manera que Gadamer (1990), en su Verdad y método, Dworkin (1986) no defiende ninguna forma de solipsismo (la respuesta correcta que defiende no es producto de una actitud de un selbstsüchtiger). Es imprescindible entender que Dworkin (1986) superó -y de modo decisivo-la filosofía de la conciencia. En otras palabras, el juez Hércules del que habla Dworkin (1986) es solo una metáfora para demostrar que la superación del paradigma representacional (muerte del sujeto solipsista de la modernidad) no ha significado la muerte del sujeto que siempre está presente en cualquier relación con el objeto.

Es decir, el linguistic-ontological-turn provocó la muerte del sujeto del esquema sujeto-objeto (el sujeto de la conciencia propia del pensamiento pensante). Pero, convengamos, eso no significa que no haya "permanecido nada en el lugar de ese sujeto". Una lectura apresurada de Dworkin (1986) (y eso también ocurre con quien lee-
Gadamer (1990) como un filólogo, hecho que sucede principalmente en el campo jurídico) da la falsa impresión de que Hércules es el portador de una "subjetividad asujetadora". Incluso François Ost (1993) comete esa equivocación al mencionar los "tres modelos de juez"4.

En realidad, así como Dworkin (1989) sufre injusticias cuando se dice que el juez Hércules es solipsista, Gadamer (1990) tampoco escapa de análisis que lo ponen indebidamente en un ambiente contrario al que se propuso en Verdad y método. En efecto, Marcelo Neves (2006) insiere al maestro de Tubinga, incorrectamente, en el contexto de un "modelo semántico-pragmático", al decir que:

En la segunda mitad del siglo XX, la teoría del derecho caminó en la dirección de considerar la interpretación del derecho sobre

Hay un texto intitulado Júpiter, Hércules, Hermes: tres modelos de juez de François Ost (1993), en el cual el profesor belga propone una especie de juez posmodernosistémico (Hermes) que actuaría en red y superaría, con gran ventaja, a los "modelos anteriores". A ese texto nosotros le hacemos una crítica que está en Verdade e consenso (2014), y también en artículo publicado en el Nevada Law Journal (Streck, 2010). Equivocación similar, aunque desde una perspectiva teórica diversa y no menos bien elaborada, es cometida por Neves al tratar de las temáticas "respuesta correcta" y "juez Hércules", verbis: "Por lo tanto, en la interpretación jurídica, no se trata aquí de extraer arbitrariamente de una infinidad de sentido de los textos normativos la decisión materializadora, en los términos de un contextualismo decisionista, pero también es insostenible la concepción ilusoria de que solo hay una solución correcta para cada caso, según los criterios de un juez hipotético racionalmente justo. La posibilidad de más de una decisión justificable a la luz de principios y reglas constitucionales me parece evidente" (2006, p. 207). En nota de fin de página $n^{\circ} 214$, el autor asocia al juez Hércules de Dworkin a ese juez "hipotético racionalmente justo". La crítica de Neves (2006) no procede. La solución apropiada (respuesta correcta) no es producto de la "mente" de Hércules (que, como ya se mencionó, es una metáfora para demostrar la superación del esquema sujeto-objeto). Dworkin deja eso bien claro, incluso -y principalmente- al ponerse de forma radical contra la discrecionalidad. Un juez que buscase respuestas según "sus propios criterios" sería exactamente el juez discrecional criticado por él, Dworkin (1989), en su debate con Hart (1994). 
todo como un problema de determinación semántica del significado de los textos jurídicos, condicionada pragmáticamente (modelo semántico-pragmático). Las operaciones sintácticas servirían para la delimitación estructural de los contornos lógico-semánticos de la interpretación. Sin embargo, la tónica del proceso hermenéutico recaería en la búsqueda del sentido normativo de textos jurídicos en contextos históricos específicos. En su formulación inicial, ese modelo remonta a la hermenéutica de Gadamer. Al intérprete del derecho cabe descubrir el sentido latente de textos normativo-jurídicos, adecuándolos al momento histórico de su aplicación al caso en cuestión.

El elemento semántico está presente, aquí, en la consideración de la variación del sentido de los textos ante su campo de denotación concreta. El aspecto pragmático se presenta en la noción de precomprensión o preconcepto del intérprete con relación a la ley del caso. Por otro lado, mientras comprende la interpretación jurídica como un proceso en el que se conoce y reconoce el sentido válido de la ley y, así, se adapta esta a las necesidades del presente, la hermenéutica no estima suficientemente la relevancia de la dimensión pragmática en el proceso de interpretación del derecho, desconociendo o, por lo menos, subestimando la función constructiva del intérprete ante los textos normativos (Neves, 2006, pp. 199-200).

Para nosotros Neves (2006) no le hace justicia a Gadamer (1990), subvalorando, principalmente, la obra Verdad y método. De hecho, se debe estudiar la hermenéutica filosófica gadameriana en el contexto del giro ontológico provocado por Heidegger, en el que rompe con las concepciones epistemológico-analíticas al introducir el mundo práctico en la filosofía (modo práctico de ser en el mundo). Por eso, Heidegger (1993) dirá que la filosofía es hermenéutica y Gadamer (1990), posteriormente, defenderá que la hermenéutica es filosófica. En ese sentido, texto es evento. Y la hermenéutica es facticidad. No se puede separar el elemento semántico del elemento pragmático en la obra de Gadamer (1990). Eso sería olvidarse de la noción de círculo hermenéutico, que fractura el esquema sujeto-objeto y el papel desempeñado por la anticipación de sentido (sin tener en cuenta, además, el rol de la diferencia ontológica, ontologische differenz). Al contrario de lo que afirma Neves (2006), Gadamer no subestima la función constructiva del intérprete. Pero ese intérprete ya no tiene los poderes del sujeto solipsista. Su hermenéutica es productiva y no reproductiva. Por eso, el maestro de Tubinga supera la interpretación como una auslegung. Para él, interpretación es sinngebung. El jurista brasileño no reconoce la gran contribución de Gadamer (1990) en la y para la superación de la cisión entre interpretary aplicar. En sentido opuesto, este reconocimiento es hecho por autores como Kaufmann (2002), Stein (2011) e Castanheira Neves (1967), para hablar solo de algunos.

Por lo tanto, no se sostienen las críticas que pretenden poner a Dworkin (1989) como defensor de un Hércules solipsista ${ }^{5}$ y a Gadamer (1990) como defensor de un "modelo semántico-pragmático" o de una hermenéutica relativista. Interpretaciones de ese tipo se muestran erradas. Pues, como ya se refirió exhaustivamente, mientras que las múltiples teorías que pretenden justificar el conocimiento buscan (buscaron) "superar" al sujeto del esquema sujeto-objeto eliminándolo o

5 En ese sentido, refutando cualquier similitud de Hércules con "arbitrariedad" o "subjetivismo", Wálber Araujo Carneiro (2011) propone la alegoría de un juez adaptado a las condiciones sistémico-institucionales del civil law $y$, en contraposición a la lectura posmoderna de Ost (1993), concibe su "juez Hermes" en una "vivienda más familiar", o sea, en el contexto hermenéutico-filosófico. El juez Hermes propuesto por Carneiro (2011, p. 315) "es responsable por traducir jurídicamente aquello que entiende a partir del mundo de la vida". Aunque Hermes haya sido preparado para moverse en el mundo institucionalizado del derecho, eso no lo convirtió en un "extranjero", pues "se vive su cotidiano en su mundo originario". La creativa relectura de la alegoría de Hermes traída por Carneiro (2011) enfrenta aún la formación académica de Hermes, en una fuerte crítica al modelo de enseñanza jurídica en Brasil, así como el "método" heterorreflexivo por él propuesto en su obra. 
sustituyéndolo por estructuras comunicacionales, redes o sistemas y, algunas de modo más radical, incluso por un pragmatismo fundado en la wille zur macht (por todas, vale referir las teorías deconstructivistas y el realismo de los critical legal studies), Dworkin (1989) y Gadamer (1990), cada uno a su manera, siempre procuraron controlar ese subjetivismo y esa subjetividad solipsista a partir de sus posturas antirrelativistas del respeto a la tradición, del virtuosismo del círculo hermenéutico, del respeto a la integridad y de la coherencia del derecho, de forma que, fundamentalmente, ambas teorías son antimetafísicas, porque rechazan, perentoriamente, los diversos dualismos que la tradición (metafísica) nos legó desde Platón. Recordemos que, tanto Dworkin (1989) como Gadamer (1990), no admiten la cisión (dualismo) entre interpretación y aplicación. $Y$ eso hace la diferencia.

Es posible afirmar, por lo tanto, que el equívoco recurrente acerca de la comprensión de las tesis de Gadamer (1990) y Dworkin (1989) -en especial, la aversión de ambos a la discrecionalidad (que, semánticamente, es atravesada a todo momento por la arbitrariedad en la atribución de sentidos)- reside en el hecho de pensar que la derrocada del esquema sujeto-objeto significó la eliminación del sujeto (presente en cualquier relación de objeto), cuya consecuencia sería un libre albedrío de sentidos (a partir de la instauración de un grado cero de sentido).

Por pensar así -y porque tienen la falta de racionalidad en la interpretación-, diversas teorías, tesis o posturas, terminaron, por un lado, regresando a aquello que pretendía combatir el método y, por otro, erigiendo discursos que exoneraran el sujeto-intérprete del encargo de elaborar discursos de fundamentación (begründungsdiskurs). Todo porque creen en la eliminación del sujeto y en su pura y sencilla sustitución por sistemas o teorías comunicativas (Habermas, 1997).

Dicho de otro modo, si el método para el paradigma representacional es/fue el supremo momento de la subjetividad, la adjudicación de su superación -como magistralmente hizo Gadamer (1990)-, no quiere decir que, a partir de entonces, sea posible "decir nada sobre nada". Al contrario: si el método ponía el lenguaje en un plano secundario (tercer elemento entre el sujeto y el objeto), manipulable por el sujeto solipsista, la intersubjetividad que se instaura con el giro lingüístico-ontológico exige que, en el interior del propio lenguaje se haga el control hermenéutico (entre otros elementos, tomar el texto en serio, circunstancia que se coaduna perfectamente con las constituciones en la segunda mitad del siglo XX y brinda especial especificidad a la interpretación del derecho, además de reafirmar la autonomía del derecho).

Es indispensable entonces, entender la problemática de la superación del esquema sujetoobjeto a partir de una visión paradigmática. Y en particular, darse cuenta de que el derecho no podría quedar inmune a esas transformaciones. Sería una incoherencia, por ejemplo, creer que tanto Gadamer (1990) como Dworkin (1989), asumieran posturas que llegasen a contradecirlos. Preguntemos, ¿qué sentido tiene pensar que Gadamer (1990), después de Verdad y método (que se debe leer como verdad contra el método), luego de promover una profunda revolución en el campo de la hermenéutica, viniera a defender posturas relativistas (con lo que sepultaría la tradición y todas sus consecuencias, principalmente la dificultad de la diferencia ontológica)? ¿Por qué motivo Dworkin (1989), después de su vehemente crítica al positivismo de Hart (1994) (con soporte en el problema de la discrecionalidad del solipsismo judicial), vendría a proponer, en lugar de ese juez hartiano, como "solución para el problema", un juez súper discrecional (o su Hércules)?

Por esas razones es que se debe hacer la lectura de Dworkin (1989) y Gadamer (1990) a partir y desde el interior del giro lingüístico-ontológico $y$, por ende, desde la superación del esquema sujeto-objeto. Una lectura aparadigmática puede generar peligrosas equivocaciones. 


\section{CONCLUSIONES}

En el plan de la hermenéutica construida desde el antirrelativismo de Gadamer (1990) y desde la igualmente antirrelativista teoría integrativa de Dworkin (1989) -cuya síntesis se encuentra en la crítica hermenéutica del derecho-, el problema de los precedentes judiciales debe entenderse no como un "mal en sí mismo", pero en la manera arbitraria que pueden ser utilizados estos por los tribunales.

Así, en Brasil hay fuertes indicios de una tentativa de fragmentación constante en la doctrina de los precedentes, instrumentalizada por el stare decisis, con una vinculación del sistema por intermedio de mecanismos creados (repercusión general o ementarios jurisprudenciales) para intentar abarcar todas las hipótesis de aplicación con un texto jurídico. Es decir, apostamos en notas textuales y nos olvidamos del aspecto cualitativo de la decisión. En consecuencia, fortalecemos la práctica inauténtica decisoria, limitándonos a producir textos que no consideren las especificidades del caso en concreto.

¿Qué hay de común a todos estos mecanismos? El intento de un concepto primordial y universalista que contenga todas las hipótesis de aplicación y olvidándose, de esta forma, del elemento hermenéutico que se manifiesta en toda experiencia jurídica. Esto es, no hay manifestación jurídica que no sea, desde siempre, interpretativa. Véase, que en el concepto de violencia intrafamiliar, por ejemplo, no están contenidas todos los millares de violencias cotidianas. La determinación concreta de lo que sea violencia intrafamiliar depende de una concreción interpretativa.

Así también la interpretación de un precedente (o cualquier otro mecanismo vinculativo) pasará por ese elemento de confrontación interpretativa. Es de la divergencia sobre la interpretación de un caso específico que emerge la respuesta, que, en los términos de la crítica hermenéutica del derecho (Streck, 2014), es llamada de adecuada a la Constitución. Así, los argumentos de principio que legitiman las decisiones judiciales deben ofrecer constreñimiento a la interpretación del precedente judicial.

Además, debe registrarse lo siguiente: aunque a sectores del pensamiento jurídico brasileño les agrade el sistema de precedentes - así como todos sus mecanismos de vinculación-, fue necesario también para Dworkin (1989) establecer las bases teóricas para hablar de respuestas correctas. Y esto es así por una razón muy simple: la vinculación es interpretativa y no normativa. La vinculación interpretativa se da desde aquello que, como demostró Gadamer (1990), se llama de universalidad hermenéutica (universalidad esta que se expresa por su carácter que no puede pasar del lenguaje, pues "ser que puede ser comprendido es lenguaje". La vinculación normativa -en el modo como estamos hablando y que es la manera por la cual la comunidad jurídica brasileña quiere "asegurar" el sistema- es aquella que se pretende hacer desde el terreno que desconsidera la radicalidad del elemento hermenéutico que traspasa la experiencia jurídica).

De la misma forma que no podemos decir cualquier cosa sobre cualquier cosa en nuestro cotidiano-porque eso nos alejaría de la "vinculación lingüística" que el modo práctico de estar en el mundo nos trae-, en la aplicación del derecho tampoco podemos decidir sobre el modo como nos parece mejor subjetivamente. En el derecho, igualmente no podemos "cambiar los nombres de las cosas". Los sentidos no son aleatorios. No hay un grado cero. Hay una cadena interpretativa que nos vincula tanto en el cotidiano como en el derecho. Así, de cada decisión se puede extraer un principio que podrá ser aplicable a los casos siguientes. Podemos llamarlo de "norteamiento de vinculación interpretativa" que se constituye a partir de la coherencia y de la integridad del derecho. Por ello, el precedente judicial se trata de un texto que solo existe interpretativamente.

\section{REFERENCIAS}

Barros, F. M. (2008). A fundamentação das decisões a partir do modelo constitucional de processo. Vol. 1. Revista do IHJ, 1(6), p. 131-148. 
Carneiro, W. A. (2011). Hermenêutica jurídica heterorreflexiva. Puerto Alegre: Livraria do Advogado.

Castanheira Neves, A. (1967). Questão de fatoquestão de direito ou o problema metodológico da juridicidade. Coimbra: Almedina.

De Oliveira, T. (2008). Decisão judicial e o conceito de princípio. Porto Alegre: Livraria do Advogado.

Dworkin, R. (1986). Law's empire. Cambridge: The Belknap Press.

Dworkin, R. (1989). Los derechos en serio. Barcelona: Ariel.

Gadamer, H. (1990). Wahrheit und methode: ergänzung register. Tübingen: J. C. B. Mohr.

Günther, K. (2004). Teoria da argumentação no direito e na moral: justificação e aplicação. São Paulo: Landy.

Habermas, J. (1997). Direito e democracia: entre faticidade e validade. V. I e II. Rio de Janeiro: Tempo Brasileiro.

Heidegger, M. (1993). Sein und Zeit. (17. ed.). Tübingen: Max Niemayer Verlag.

Jestaedt, Matthias. (2002). Verfassungsgerichtspositivismus. Die Ohnmacht des Verfassungsgesetzgebers im verfassungsgerichtlichen Jurisdiktionsstat, In: Depenheuer, Otto, et al (Hg.). Nomos und Ethos, Hommage an Josef Isensee zum 65. Geburstag von seinen Schüllern. Berlin: Duncker \& Humbolt. p 183-228.
Jestaedt, M. (2008). La ponderación en el derecho. En: E. Montealegre (org). El derecho público: una ciencia. Bogotá: Universidad Externado de Colombia.

Kaufmann, A. (2002). Introdução à filosofía do direito e à teoria do direito contemporâneas. Lisboa: Fundação Calouste Gulbenkian.

Kelsen, H. (1979). Teoria pura do direito. Coimbra: Arménio Amado.

Müller, F. (2005). Métodos de trabalho do direito constitucional. ( $3^{\mathrm{a}}$ ed.). Rio de Janeiro: Zahar.

Neves, M. (2006), Entre Têmis e Leviatã: uma relação difícil. São Paulo: Martins Fontes.

Ost, F. (1993). Júpiter, Hércules, Hermes: tres modelos de juez. Doxa. Cuadernos de Filosofía del Derecho, (14), p. 169-194.

Stein, E. \& Streck, L. (orgs.). (2011). Hermenêutica e epistemologia: 50 anos de Verdade e método. Puerto Alegre: Livraria do Advogado.

Streck, L. L. (2010). Deconstructing the models of judges: legal hermeneutics and beyond the subject-object paradigm. Nevada Law Journal, 10(3), p. 683-699.

Streck, L. L. (2014). Verdade e consenso: Constituição, hermenêutica e teorias discursivas (5a ed.). São Paulo: Saraiva.

Tribe, L. \& Dorf, M. (2006). Hermenêutica constitucional. Belo Horizonte: Del Rey. 